\title{
Mortality patterns in Vietnam, 2006: Findings from a national verbal autopsy survey
}

\author{
Anh D Ngo ${ }^{*}$, Chalapati Rao ${ }^{1}$, Nguyen Phuong Hoa ${ }^{2}$, Timothy Adair ${ }^{1}$, Nguyen Thi Kim Chuc ${ }^{2}$
}

\begin{abstract}
Background: Accurate nationally representative statistics on total and cause-specific mortality in Vietnam are lacking due to incomplete capture in government reporting systems. This paper presents total and cause-specific mortality results from a national verbal autopsy survey conducted first time in Vietnam in conjunction with the annual population change survey and discusses methodological and logistical challenges associated with the implementation of a nation-wide assessment of mortality based on surveys.

Verbal autopsy interviews, using the WHO standard questionnaire, were conducted with close relatives of the 6798 deaths identified in the 2007 population change survey in Vietnam. Data collectors were health staff recruited from the commune health station who undertook 3-day intensive training on VA interview. The Preston-Coale method assessed the level of completeness of mortality reporting from the population change survey. The number of deaths in each age-sex grouping is inflated according to the estimate of completeness to produce an adjusted number of deaths. Underlying causes of death were aggregated to the International Classification of Diseases Mortality Tabulation List 1. Leading causes of death were tabulated by sex for three broad age groups: 0-14 years; 1559 years; and 60 years and above.
\end{abstract}

Findings: Completeness of mortality reporting was $69 \%$ for males and $54 \%$ for females with substantial regional variation. The use of VA has resulted in 10\% of deaths being classified to ill-defined among males, and 15\% among females. More ill-defined deaths were reported among the 60 year or above age group. Incomplete death reporting, wide geographical dispersal of deaths, extensive travel between households, and substantial variation in local responses to VA interviews challenged the implementation of a national mortality and cause of death assessment based on surveys.

Conclusions: Verbal autopsy can be a viable tool to identify cause of death in Vietnam. However logistical challenges limit its use in conjunction with the national sample survey. Sentinel population clusters for mortality surveillance should be tested to develop an effective and sustainable option for routine mortality and cause of death data collection in Vietnam.

\section{Background}

Vietnam has experienced a demographic transition characterized by decreasing fertility rates in the past two decades and marked improvements in child survival $[1,2]$. Historical demographic trends have shown that such changes lead to increasing longevity and population aging, accompanied by a shift in disease burden from infectious to non-communicable diseases [3]. Reliable data on patterns of mortality and causes of death is critical to monitor such transitions, and to support the

\footnotetext{
* Correspondence: n.anh@sph.uq.edu.au

'Vietnam Evidence for Health Policy Project, School of Population Health, University of Queensland, 138 Giang Vo Str, Hanoi, Vietnam
}

development of evidence-based health policy to minimise avoidable adult mortality. Unfortunately, accurate nationally representative statistics on total and causespecific mortality in Vietnam are lacking due to inadequate routine information systems [4]. The only available information on mortality levels and patterns is from the Fila Bavi, a demographic surveillance site covering a population of roughly 50,000 located in a rural district about $100 \mathrm{~km}$ north of Hanoi [5,6]. These data are limited to a small sample size, narrow geographic coverage, and pertain to a population that does not represent the socio-economic characteristics of Vietnam in general. 
To monitor population and demographic indicators in Vietnam, the General Statistics Office (GSO) has been operating an annual population change survey (PCS) in a nationally representative population sample since 2000 [2]. Analysis of 2004, 2005, and 2006 mortality data from this survey indicated severe deficiency in death reporting, ranging between $39 \%$ to $59 \%$ for the whole country [7]. During 2007 - 2008, a research project was undertaken to improve the completeness of death reporting from the PCS conducted in 2007, and to use verbal autopsy (VA) methods to ascertain the cause of reported deaths. This project is a step towards the expanded use of VA to develop a longterm, national mortality data collection system in Vietnam. This paper presents total and cause-specific mortality results from the project, highlights methodological and logistical challenges in conducting a nation-wide assessment of mortality based on surveys, and discusses future strategies for routine mortality data collection in Vietnam.

\section{Data and Methods}

The annual PCS is implemented in a nationally representative population sample derived through multi-stage stratified cluster sampling. The primary sampling unit is the Enumeration Area (EA) defined in the 1999 population census, which on average comprises approximately 100 households. Each year, a fresh sample of EAs is drawn from these pre-defined EAs. A total of 3840 EAs in the 64 provinces of Vietnam were included in the 2007 survey, covering about $2 \%$ of the national population.

The PCS in April 2007 collected information on deaths reported by households to have occurred between $1^{\text {st }}$ April 2006 and $31^{\text {st }}$ March, 2007. For each death, demographic information of the deceased (e.g., age, sex, date of death) and household address were used to locate the household for subsequent VA interviews with the principal care taker of the deceased. For national application of VA, the WHO standard VA questionnaire [8] was adapted to the Vietnamese context, based on experience with VA in the Fila Bavi demographic surveillance site [5,6]. (see Additional file 1).

Support for training, fieldwork supervision and data management, was provided by 5 medical universities, including Thai Nguyen, Hanoi in the North, Hue in the centre, and Ho Chi Minh and Can Tho in the South. For logistical convenience, 64 provinces were divided into 5 clusters (Figure 1), corresponding with the location of each medical university. VA interviews were completed in 6 months from September 2007 to April 2008, excluding 2 months of New Year (January and February 2008). Filled questionnaires were reviewed by a team of experienced medical doctors at each medical

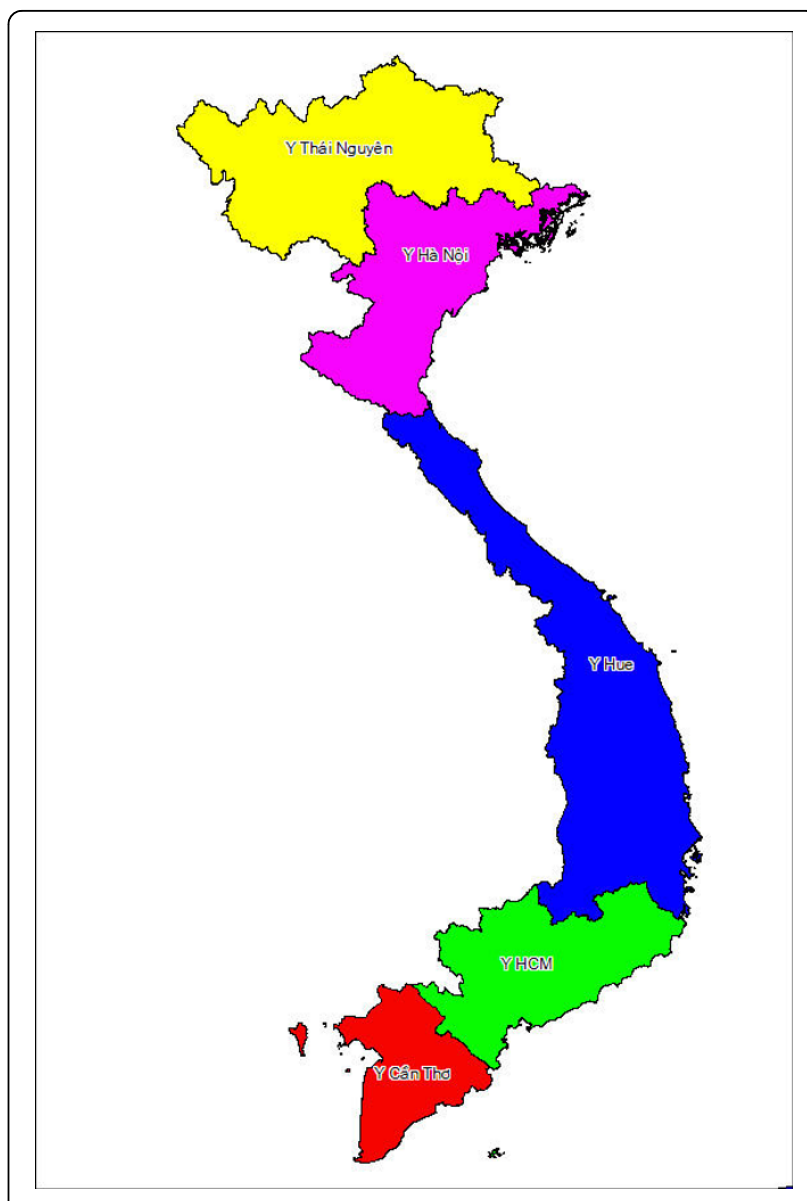

Figure 1 VA interview cluster and the corresponding medical university

university, who then assigned the causes of death following the standard death certification form [8]. Underlying causes of death were selected and coded using ICD Version10 (ICD-10).

\section{Statistical analysis}

The Preston-Coale method [9] was used to assess the level of completeness of mortality reporting from the GSO PCS (see Additional file 2 for details). The results were used to adjust observed age-specific mortality rates and compute life tables for all Vietnam and each region. Life expectancy estimates at the regional level were calculated along with $95 \%$ confidence intervals using the Chiang Silcock method [10].

For statistical presentation, underlying causes of death were aggregated to the International Classification of Diseases (ICD) Mortality Tabulation List 1. Leading causes of death were tabulated by sex for three broad age groups: $0-14$ years; $15-59$ years; and 60 years and above. 


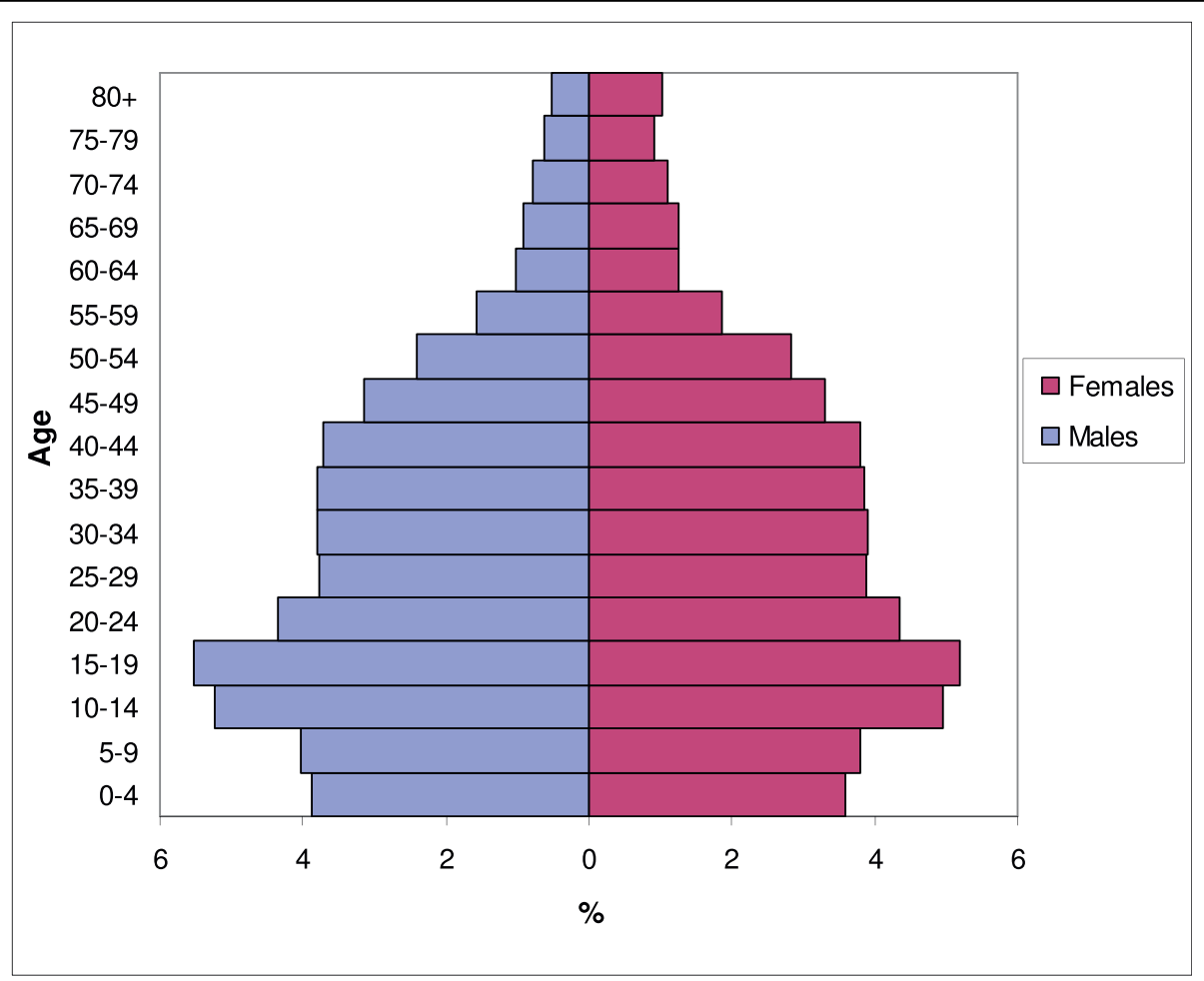

Figure 2 Population pyramid for Vietnam as observed from PCS 2007.

\section{Results}

Figure 2 shows the age-sex structure of the 2007 survey population. The decline in fertility in the past two decades can be observed from the population proportions in the younger age groups, and this is observed in the population pyramids across all regions.

\section{All cause mortality}

The 2007 PCS identified 7124 deaths for VA follow up interviews. The estimated completeness of mortality reporting in Vietnam was $69 \%$ for males and 54\% for females. For males, the completeness ranges from $60 \%$ to $75 \%$, while for females it ranges from $45 \%$ to $62 \%$ (Table 1). The figure of over $100 \%$ for each sex in Central Highlands is clearly incorrect, and suggests that the assumption of population stability has been breached. Hence, we chose not to compute life tables for this region because of this uncertainty.

At the national level, estimated life expectancy at birth (LE) is approximately seven years higher for females (73.7 years) compared with males (66.4). These estimates approximate the World Health Organization's estimates for Vietnam in 2006 (75 years for females, and
Table 1 Completeness of mortality reporting and adjusted summary mortality measures by region, males and females, Vietnam, GSO Survey 2007

\begin{tabular}{|c|c|c|c|c|c|c|c|c|}
\hline \multirow[b]{2}{*}{ Region } & \multicolumn{4}{|c|}{ Males } & \multicolumn{4}{|c|}{ Females } \\
\hline & Compl. & U5MR & Adult & $\mathrm{e}_{0}$ & Compl. & U5MR & Adult & $\mathrm{e}_{0}$ \\
\hline Vietnam & 69.0 & 23.0 & 266 & 66.4 & 54.2 & 26.9 & 118 & 73.7 \\
\hline $\begin{array}{l}\text { Red River } \\
\text { Delta }\end{array}$ & 69.4 & 17.9 & 237 & 67.8 & 55.2 & 12.6 & 127 & 76.0 \\
\hline Northeast & 68.4 & 39.0 & 340 & 60.7 & 45.7 & 50.7 & 134 & 69.3 \\
\hline Northwest & 66.2 & 51.2 & 346 & 60.0 & 62.3 & 77.0 & 114 & 68.7 \\
\hline $\begin{array}{l}\text { North } \\
\text { Central }\end{array}$ & 74.6 & 21.9 & 302 & 66.7 & 58.4 & 29.9 & 79 & 75.5 \\
\hline $\begin{array}{l}\text { South } \\
\text { Central } \\
\text { Coast }\end{array}$ & 64.4 & 24.4 & 278 & 67.3 & 53.8 & 26.0 & 114 & 74.6 \\
\hline $\begin{array}{l}\text { Central } \\
\text { Highlands }\end{array}$ & 134.9 & - & - & - & 119.9 & - & - & - \\
\hline Southeast & 73.5 & 10.0 & 228 & 69.1 & 60.8 & 10.4 & 97 & 76.4 \\
\hline $\begin{array}{l}\text { Mekong } \\
\text { River } \\
\text { Delta }\end{array}$ & 60.2 & 23.5 & 259 & 65.9 & 45.2 & 29.9 & 153 & 69.9 \\
\hline
\end{tabular}

Compl.: Completeness of mortality reporting (\%) U5MR: Under-five mortality rate per 1,000 births Adult: Adult mortality rate per 1,000 (15-59 years) $\mathrm{e}_{0}$ : Life expectancy at birth (years) 
69 years for males) [11] LE was significantly lower for both males and females in the Northeast and Northwest regions as compared to other regions, based on 95\% confidence intervals, These differences largely reflect the variations in the adjusted levels of adult mortality between males and females, and across regions, as listed in Table 1.

\section{Cause specific mortality}

VA interview was completed in 6798 cases (response rate was $95 \%$ ). The main reasons for non-responses were inability to locate the household due to household moving out, wrong or incomplete address provided by the PCS, or inconsistent use of the name of the head of the household (i.e., nickname, husband's name; first son's name). Only 10 households refused to attend the interview.

Tables 2, 3, 4, 5, 6, 7 present the proportionate cause of death findings for different age groups and all ages. For children aged under 15 years, perinatal conditions is the leading cause of death for both males and females. External causes are prominent in this age group; accidental drowning is a major cause for borth sexes ( $13 \%$ for males, $11 \%$ for females) while transport accidents is the $4^{\text {th }}$ leading cause for males $(6 \%)$.

The cause-specific mortality results for the 15-59 years age group provides insight into the reasons for the large sex differential in the adult mortality rate. The leading causes of male mortality are transport accidents, cerebrovascular diseases HIV/AIDS, liver cancer and other diseases of liver. Tuberculosis is also a leading cause for this age group (4\%). For females, there are some similarities in the rank order of leading causes, but with clearly fewer deaths from each cause.

In both sexes, nearly one fourth of deaths above 60 years are caused by cerebrovascular diseases. Other major causes include chronic lower respiratory diseases, hypertensive diseases, ischaemic heart diseases and tuberculosis. It is interesting to note that lung cancer is a major cause in men, probably a result of the tobacco epidemic. Ill-defined causes are also prominent in this age group, underscoring the limitations of VA in cause of death ascertainment in the elderly. The leading causes of death across all ages (see Table 5) indicate that non-

Table 2 Leading causes of death, 0-14 years, Vietnam, 2006-07

\begin{tabular}{|c|c|c|c|c|c|c|c|}
\hline \multicolumn{3}{|c|}{ Males } & \multicolumn{5}{|c|}{ Females } \\
\hline & Cause & $\mathbf{N}$ & $\%$ & & Cause & $\mathbf{N}$ & $\%$ \\
\hline 1 & Perinatal conditions & 62 & 20.9 & 1 & Perinatal conditions & 47 & 22.5 \\
\hline 2 & Accidental drowning & 38 & 12.8 & 2 & Pneumonia & 34 & 16.3 \\
\hline 3 & Pneumonia & 34 & 11.4 & 3 & Accidental drowning & 23 & 11.0 \\
\hline 4 & Transport accidents & 19 & 6.4 & 4 & Congenital malformations & 14 & 6.7 \\
\hline 5 & Congenital malformations & 16 & 5.4 & 5 & Remainder of diseases of digestive system & 13 & 6.2 \\
\hline & III-defined & 19 & 6.4 & & III-defined & 16 & 7.7 \\
\hline & All other causes & 109 & 36.7 & & All other causes & 62 & 29.7 \\
\hline & Total & 297 & & & Total & 209 & \\
\hline
\end{tabular}

Table 3 Leading causes of death, 15-59 years, Vietnam, 2006-07

\begin{tabular}{|c|c|c|c|c|c|c|c|}
\hline \multicolumn{3}{|c|}{ Males } & \multicolumn{5}{|c|}{ Females } \\
\hline & Cause & $\mathbf{N}$ & $\%$ & & Cause & $\mathbf{N}$ & $\%$ \\
\hline 1 & Transport accidents & 264 & 15.3 & 1 & Transport accidents & 60 & 10.5 \\
\hline 2 & Cerebrovascular diseases & 132 & 7.7 & 2 & Cerebrovascular diseases & 47 & 8.2 \\
\hline 3 & HIV/AIDS & 105 & 6.1 & 3 & Liver cancer & 31 & 5.4 \\
\hline 4 & Liver cancer & 97 & 5.6 & 4 & Suicide & 24 & 4.2 \\
\hline 5 & Other external causes & 86 & 5.0 & 5 & Other heart diseases & 22 & 3.8 \\
\hline 6 & Liver diseases & 83 & 4.8 & 6 & Stomach cancer & 19 & 3.3 \\
\hline 7 & Accidental drowning & 65 & 3.8 & 7 & Colon, rectum, anus cancer & 18 & 3.1 \\
\hline 8 & Tuberculosis & 62 & 3.6 & 8 & Other cancer of uterus & 17 & 3.0 \\
\hline 9 & Suicide & 61 & 3.5 & 9 & Accidental drowning & 17 & 3.0 \\
\hline \multirow[t]{4}{*}{10} & Lung cancer & 58 & 3.4 & 10 & Breast cancer & 17 & 3.0 \\
\hline & III-defined & 124 & 7.2 & & III-defined & 27 & 4.7 \\
\hline & All other causes & 588 & 34.1 & & All other causes & 273 & 47.7 \\
\hline & Total & 1725 & & & Total & 572 & \\
\hline
\end{tabular}


Table 4 Leading causes of death, 60 years and above, Vietnam, 2006-07

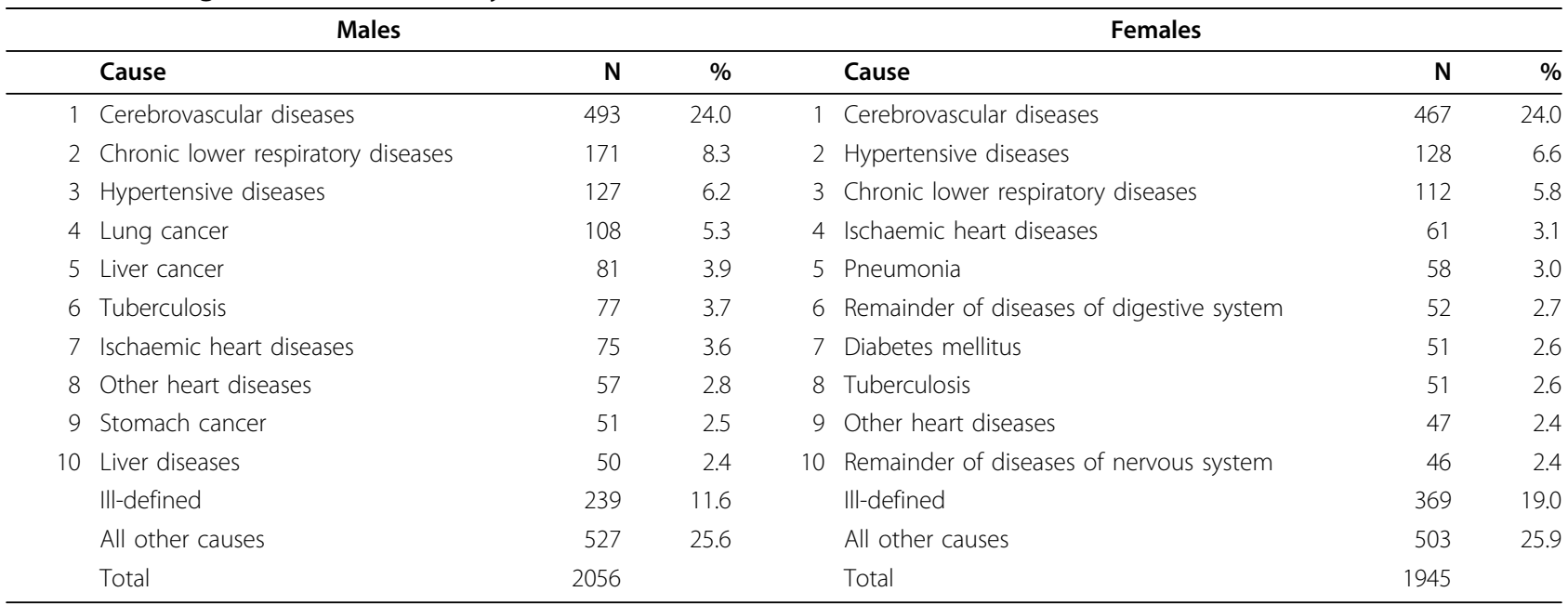

Table 5 Leading causes of death, all ages, Vietnam, 2006-07

\begin{tabular}{|c|c|c|c|c|c|c|c|}
\hline \multicolumn{4}{|c|}{ Males } & \multicolumn{4}{|c|}{ Females } \\
\hline & Cause & $\mathbf{N}$ & $\%$ & & Cause & $\mathbf{N}$ & $\%$ \\
\hline 1 & Cerebrovascular diseases & 628 & 15.4 & 1 & Cerebrovascular diseases & 517 & 19.0 \\
\hline 2 & Transport accidents & 328 & 8.0 & 2 & Hypertensive diseases & 140 & 5.1 \\
\hline 3 & Chronic lower respiratory diseases & 209 & 5.1 & 3 & Chronic lower respiratory diseases & 127 & 4.7 \\
\hline 4 & Liver cancer & 179 & 4.4 & 4 & Pneumonia & 102 & 3.7 \\
\hline 5 & Lung cancer & 166 & 4.1 & 5 & Transport accidents & 86 & 3.2 \\
\hline 6 & Hypertensive diseases & 156 & 3.8 & 6 & Liver cancer & 75 & 2.8 \\
\hline 7 & Tuberculosis & 141 & 3.5 & 7 & Ischaemic heart diseases & 74 & 2.7 \\
\hline 8 & Diseases of the liver & 136 & 3.3 & 8 & Other heart diseases & 72 & 2.6 \\
\hline 9 & Ischaemic heart diseases & 129 & 3.2 & 9 & Remainder of diseases of digestive system & 71 & 2.6 \\
\hline 10 & All other external & 125 & 3.1 & 10 & Remainder of diseases of nervous system & 64 & 2.3 \\
\hline & III-defined & 382 & 9.4 & & III-defined & 412 & 15.1 \\
\hline & All other causes & 1499 & 36.8 & & All other causes & 987 & 36.2 \\
\hline & Total & 4078 & & & Total & 2727 & \\
\hline
\end{tabular}

communicable diseases and injuries account for the bulk of the burden from premature mortality in Vietnam.

In addition to leading causes of death, a comprehensive summary of the cause of death distribution by broad age group and sex is presented in Tables 6 and 7 . For ease in interpretation, causes of death were aggregated to ICD 10 chapters for categorical presentation. These tables enhance the appreciation of the magnitude of broad categories such as injuries, circulatory system diseases, infectious diseases etc as causes of mortality at different ages.

\section{Discussion}

This paper presents the first ever findings on nationwide total and cause specific mortality patterns in Vietnam. Although there are several constraints in the quality of the data, the broad findings from the study have important implications for Vietnam. Firstly, the adjusted estimates of life expectancy at birth and levels of adult mortality are consistent with previously observed mortality time trends in Vietnam [12] and demonstrate steady improvements in population health status in Vietnam over the past three decades. Secondly, important differences were noted when our results on causespecific mortality are compared with the findings from the VA study of 189 deaths in Fila-Bavi in 1999 [5]. While diseases of the circulatory system, cancers, and accidents were the three prominent causes of deaths among all age groups in both studies, infectious diseases, prenatal and neonatal causes were not among 10 leading causes in our study. These differences are important, but unsurprising, given the relatively small sample and rural setting of the Fila-Bavi demographic surveillance site.

Overall, the use of VA has resulted in about $10 \%$ of deaths being classified to ill-defined conditions among males, and $15 \%$ in females, which is acceptable given the 
Table 6 Causes of death by ICD-10 chapter, males, Vietnam, 2007

\begin{tabular}{|c|c|c|c|c|c|c|c|c|c|}
\hline \multirow{2}{*}{\multicolumn{2}{|c|}{ ICD-10 Chapter }} & \multicolumn{2}{|c|}{$0-14$ years } & \multicolumn{2}{|c|}{$15-59$ years } & \multicolumn{2}{|c|}{$60+$ years } & \multicolumn{2}{|c|}{ All ages } \\
\hline & & \multirow{2}{*}{$\frac{\mathbf{N}}{22}$} & \multirow{2}{*}{$\begin{array}{r}\% \\
7.4\end{array}$} & \multirow{2}{*}{$\frac{\mathbf{N}}{195}$} & \multirow{2}{*}{$\begin{array}{r}\% \\
11.3\end{array}$} & \multirow{2}{*}{$\frac{\mathbf{N}}{90}$} & \multirow{2}{*}{$\begin{array}{r}\% \\
4.4\end{array}$} & \multirow{2}{*}{$\frac{\mathbf{N}}{306}$} & \multirow{2}{*}{$\begin{array}{r}\% \\
7.5\end{array}$} \\
\hline । & Infectious and parasitic & & & & & & & & \\
\hline$\|$ & Neoplasms & 11 & 3.7 & 355 & 20.6 & 406 & 19.7 & 775 & 19.0 \\
\hline IV & Endocrine, nutritional and metabolic & 5 & 1.7 & 15 & 0.9 & 5 & 0.2 & 25 & 0.6 \\
\hline $\mathrm{Vl}$ & Nervous system & 13 & 4.4 & 29 & 1.7 & 25 & 1.2 & 67 & 1.6 \\
\hline IX & Circulatory system & 7 & 2.4 & 229 & 13.3 & 754 & 36.7 & 990 & 24.3 \\
\hline$x$ & Respiratory system & 43 & 14.5 & 57 & 3.3 & 231 & 11.2 & 331 & 8.1 \\
\hline$X I$ & Digestive system & 14 & 4.7 & 119 & 6.9 & 98 & 4.8 & 231 & 5.7 \\
\hline XIV & Genitourinary & 3 & 1.0 & 16 & 0.9 & 19 & 0.9 & 38 & 0.9 \\
\hline $\mathrm{XVI}$ & Perinatal & 68 & 22.9 & 0 & 0.0 & 0 & 0.0 & 62 & 1.5 \\
\hline $\mathrm{XVII}$ & Congenital malformations & 16 & 5.4 & 2 & 0.1 & 0 & 0.0 & 18 & 0.4 \\
\hline$X V I I I$ & Symptoms etc not elsewhere classified & 19 & 6.4 & 124 & 7.2 & 239 & 11.6 & 382 & 9.4 \\
\hline \multirow[t]{3}{*}{$X I X / X X$} & Injuries and external causes & 72 & 24.2 & 544 & 31.5 & 128 & 6.2 & 744 & 18.2 \\
\hline & All other chapters & 4 & 1.3 & 40 & 2.3 & 61 & 3.0 & 109 & 2.7 \\
\hline & Total & 297 & & 1725 & & 2056 & & 4078 & \\
\hline
\end{tabular}

Table 7 Causes of death by ICD-10 chapter, females, Vietnam, 2007

\begin{tabular}{|c|c|c|c|c|c|c|c|c|}
\hline \multirow[b]{2}{*}{ ICD-10 Chapter } & \multicolumn{2}{|c|}{$0-14$ years } & \multicolumn{2}{|c|}{$15-59$ years } & \multicolumn{2}{|c|}{$60+$ years } & \multicolumn{2}{|c|}{ All ages } \\
\hline & $\mathrm{N}$ & $\%$ & $\mathrm{~N}$ & $\%$ & $\mathrm{~N}$ & $\%$ & $\mathrm{~N}$ & $\%$ \\
\hline I Infectious and parasitic & 16 & 7.7 & 38 & 6.6 & 85 & 4.4 & 139 & $\overline{5.1}$ \\
\hline ॥ Neoplasms & 5 & 2.4 & 168 & 29.4 & 256 & 13.2 & 429 & 15.7 \\
\hline IV Endocrine, nutritional and metabolic & 3 & 1.4 & 14 & 2.4 & 54 & 2.8 & 71 & 2.6 \\
\hline VI Nervous system & 10 & 4.8 & 15 & 2.6 & 66 & 3.4 & 91 & 3.3 \\
\hline IX Circulatory system & 7 & 3.3 & 101 & 17.7 & 706 & 36.3 & 814 & 29.8 \\
\hline X Respiratory system & 37 & 17.7 & 23 & 4.0 & 187 & 9.6 & 247 & 9.1 \\
\hline XI Digestive system & 14 & 6.7 & 21 & 3.7 & 81 & 4.2 & 116 & 4.3 \\
\hline XIV Genitourinary & 0 & 0.0 & 11 & 1.9 & 21 & 1.1 & 32 & 1.2 \\
\hline XV Pregnancy \& childbirth & 3 & 1.4 & 5 & 0.9 & 1 & 0.1 & 9 & 0.3 \\
\hline XVI Perinatal & 47 & 22.5 & 0 & 0.0 & 0 & 0.0 & 47 & 1.7 \\
\hline XVII Congenital malformations & 14 & 6.7 & 0 & 0.0 & 0 & 0.0 & 14 & 0.5 \\
\hline XVIII Symptoms etc not elsewhere classified & 16 & 7.7 & 27 & 4.7 & 369 & 19.0 & 412 & 15.1 \\
\hline XIX/XX Injuries and external causes & 37 & 17.7 & 126 & 22.0 & 82 & 4.2 & 245 & 9.0 \\
\hline All other chapters & 0 & 0.0 & 23 & 4.0 & 38 & 2.0 & 61 & 2.2 \\
\hline Total & 209 & & 572 & & 1946 & & 2727 & \\
\hline
\end{tabular}

challenges in diagnosing causes of death from this method. In old age (60 years or older), the proportion of deaths classifiable is lowest compared to that in other age groups, a similar finding to studies in India that reported VA is a less reliable to ascertain cause of death for older age [13,14].

Despite the incompleteness of death recording, the proportionate mortality by cause at different ages provides an empirical basis for understanding health priorities. The findings suggest a clear need to improve health services to control perinatal mortality, and the need for evidence based interventions to reduce deaths from traffic accidents and drowning. Among adults, the observation that cerebrovascular disease causes about 5 times the number of deaths as ischemic heart diseases (IHD)calls for more detailed research into the epidemiology of these conditions, and the implementation of primary and secondary prevention strategies. This ratio could be skewed on account of IHD deaths being misclassified as deaths from hypertensive diseases, which is observed to cause about double the proportion of deaths from IHD at ages 60 and over. This requires careful evaluation through assessment of the reliability and/or validity of VA application in Vietnam. Additional findings for males include the emergence of HIV/AIDS as a leading cause of death at ages 15-59 years, and tuberculosis as the seventh leading cause of death at all ages. All these findings signify the need to improve surveillance and treatment programs for these conditions. 
From an operational perspective, integration of activities to measure cause-specific mortality with the existing annual national PCS offered several advantages. Firstly, it saved resources that otherwise would be needed for identification of deaths in a nationally representative sample, given incomplete vital registration in Vietnam. Secondly, mortality data provided by GSO is legally recognized by the government of Vietnam, and therefore, the results from the study can inform policy development. In this regard, activities in this project to strengthen death recording by GSO staff did result in improvement in the completeness of data. More importantly, however, the activity enabled 5 medical universities throughout the country to develop experience in the systematic investigation of cause of death on a nationwide scale, using the VA method. This has created an institutional network in different regions, which is a sound platform for routine and sustained implementation of cause-specific mortality data collection systems in all parts of Vietnam.

However, despite the operational advantages described above, the GSO annual PCS presented significant challenges in translating the data collected into reliable information for routine mortality measurement. Firstly, a principal issue with the data is the low completeness of deaths recorded by surveyors (see Additional File 2). Secondly, there were several challenges in the implementation of VA interviews in conjunction with the survey (see Additional File 1). Hence, while this exercise has proved to be a valuable experience as the first ever national level mortality and cause of death data collection in Vietnam, more effective and sustainable options are required for routine implementation. To meet this challenge, sentinel mortality surveillance sites are being tested in 2009. The proposed sentinel sites comprise 192 communes in 16 provinces, covering an optimal sample population given the mortality profile for Vietnam [15]. At the commune level, data collection efforts involve the collaboration of the official civil registration system, the commune health station, and local 'population collaborators' from the Population and Family Planning Department of the Ministry of Health. The tools, methods, and experiences from the current study would be used together with technical support from the five medical universities. Continuous data collection in these sites over the next 5-10 years, supported by appropriately designed studies to validate reported causes of death, would yield valuable evidence on current mortality patterns and trends, to inform health policy and epidemiological research in Vietnam.

\section{Conclusion}

This study provides evidence that verbal autopsy can be a viable tool to identify cause of death in Vietnam.
However, its use in conjunction with the national sample survey is limited by incomplete death reporting as well as logistical challenges in implementing household VA interviews. The proposed sentinel mortality surveillance sites being tested in 2009, using tools, methods and experiences from the current study, will help better understand the applicability of the VA method and develop effective and sustainable systems for routine mortality assessment in Vietnam.

\section{Additional file 1: Verbal autopsy methods and limitations. This file describes the application of the VA method in the study, the challenges and limitations of VA implementation. \\ Click here for file \\ [http://www.biomedcentral.com/content/supplementary/1756-0500-3-78- S1.DOC] \\ Additional file 2: Completeness of death reporting in the GSO survey, 2007. This file presents measures undertaken to improve the completeness of death reporting in the 2007 GSO survey and describes methods used to estimate the completeness of death recording in this survey. \\ Click here for file \\ [ http://www.biomedcentral.com/content/supplementary/1756-0500-3-78- S2.DOC]}

\section{List of abbreviations used}

EA: Enumeration area; GSO: General Statistics Office; Ischemic heart diseases: IHD; LE: Life expectancy at birth; PCS: Population change survey; VA: Verbal autopsy.

\section{Acknowledgements}

This study is part of the Vietnam Evidence for Health Policy Project, funded by Atlantic Philanthropies. The authors would like to thank the research team from five medical universities for their valuable contributions to implementing the VA survey.

\section{Author details}

'Vietnam Evidence for Health Policy Project, School of Population Health, University of Queensland, 138 Giang Vo Str, Hanoi, Vietnam. ${ }^{2}$ Hanoi Medical University, Ton That Tung Str, Hanoi, Vietnam.

\section{Authors' contributions}

CR conceived research ideas. AN, CR, NTPH and NTKC developed research protocol, data collection tools, and conduct data collection and data entry TA performed data analysis. AN drafted the manuscript with input from all other authors. All authors reviewed and approved the final version.

\section{Competing interests}

The authors declare that they have no competing interests.

Received: 5 November 2009 Accepted: 18 March 2010

Published: 18 March 2010

\section{References}

1. Ministry of Health: Demographic Surveillance Survey. Hanoi 2002.

2. General Statistic Office: The 2007 population change and family planning survey: Major findings. Statistics Publishing House: Hanoi 2008.

3. Omran A: Epidemiologic transition: a theory of the epidemiology of population change. Milbank Memorial Fund Quarterly 1971, 49:509-538.

4. Huy $\mathrm{TQ}$, Johansson $\mathrm{A}$, Long $\mathrm{NH}$ : Reasons for not reporting deaths: a qualitative study in rural Vietnam. World Health Popul 2007, 9(1):14-23.

5. Huong DL MH, Byass P: Applying verbal autopsy to determine cause of death in rural Vietnam. Scand J Public Health 2003, 31(suppl 62):19-25.

6. Minh HV HD, Wall S, Nguyen TK, Byass P: Cardiovascular disease mortality and its association with socioeconomic status: findings from a 
population-based cohort study in rural Vietnam,1999-2003. Prev Chronic Dis 2006, 3(3):A89.

7. General Statistic Office: Assessment of completeness of mortality data in 2005, and 2006 population change survey. Statistics Publishing House: Hanoi 2004.

8. WHO: Verbal autopsy standards. Ascertaining and Attributing Cause of Death. Geneva 2007.

9. Preston S, Coale AJ, Trussell J, Weinstein M: Estimating the completeness of reporting of adult deaths in populations that are approximately stable. Popul Index 46(2):179-202.

10. Schoen R: Calculating life tables by estimating Chiang's alpha from observed rates. Demography 1978, 15(4):625-635.

11. World Health Organization: World Health Statistics, 2008 2008, [http://www. who.int/countries/vnm/en/], [cited 2010 February].

12. Banner M: Vietnam: A reconstitution of its $20^{\text {th }}$ century population history. Asian Historical Statistics (AHSTAT) COE Project. Institute of Economic Research-Hitotsubashi University: Tokyo 2000.

13. Gajalakshmi V, Peto R, Kanaka S, Balasubramanian S: Verbal autopsy of 48 000 adult deaths attributable to medical causes in Chennai (formerly Madras), India. BMC Public Health 2002, 2(7).

14. Gajalakshmi V, Peto R: Verbal autopsy of 80,000 adult deaths in Tamilnadu, South India. BMC Public Health 2004, 4(47)

15. Begg S, Rao C, Lopez AD: Design options for sample-based mortality surveillance. International Journal of Epidemiology 2005, 34(5):1080-87.

doi:10.1186/1756-0500-3-78

Cite this article as: Ngo et al:: Mortality patterns in Vietnam, 2006: Findings from a national verbal autopsy survey. BMC Research Notes 2010 3:78.

\section{Submit your next manuscript to BioMed Central and take full advantage of:}

- Convenient online submission

- Thorough peer review

- No space constraints or color figure charges

- Immediate publication on acceptance

- Inclusion in PubMed, CAS, Scopus and Google Scholar

- Research which is freely available for redistribution

Submit your manuscript at www.biomedcentral.com/submit 